\title{
Assessing geographical differences in illicit drug consumption - A comparison of results from epidemiological and wastewater data in Germany and Switzerland
}

Been, F ; Bijlsma, L ; Benaglia, L ; Botero-Coy, A M ; Castiglioni, S ; Kraus, L ; Zobel, F ; Schaub, Michael P ; Bücheli, A ; Hernandez, F ; Delémont, O ; Esseiva, P ; Ort, C

DOI: https://doi.org/10.1016/j.drugalcdep.2016.02.002

Posted at the Zurich Open Repository and Archive, University of Zurich

ZORA URL: https://doi.org/10.5167/uzh-126932

Journal Article

Accepted Version

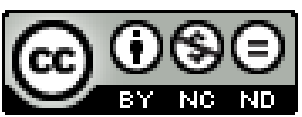

The following work is licensed under a Creative Commons: Attribution-NonCommercial-NoDerivatives 4.0 International (CC BY-NC-ND 4.0) License.

Originally published at:

Been, F; Bijlsma, L; Benaglia, L; Botero-Coy, A M; Castiglioni, S; Kraus, L; Zobel, F; Schaub, Michael P; Bücheli, A; Hernandez, F; Delémont, O; Esseiva, P; Ort, C (2016). Assessing geographical differences in illicit drug consumption - A comparison of results from epidemiological and wastewater data in Germany and Switzerland. Drug and Alcohol Dependence, (161):189-199.

DOI: https://doi.org/10.1016/j.drugalcdep.2016.02.002 
Full length article

\title{
Assessing geographical differences in illicit drug consumption-A comparison of results from epidemiological and wastewater data in Germany and Switzerland
}

\author{
Frederic Been ${ }^{a}$, Lubertus Bijlsma ${ }^{b}$, Lisa Benaglia ${ }^{a}$, Jean-Daniel Berset ${ }^{c}$, \\ Ana M. Botero-Coy ${ }^{\mathrm{b}}$, Sara Castiglioni ${ }^{\mathrm{d}}$, Ludwig Kraus ${ }^{\mathrm{e}, \mathrm{f}}$, Frank Zobel ${ }^{\mathrm{g}}$, Michael P. Schaub ${ }^{\mathrm{h}}$, \\ Alexander Bücheli ${ }^{i}$, Félix Hernández ${ }^{\mathrm{b}}$, Olivier Delémont ${ }^{\mathrm{a}}$, Pierre Esseiva ${ }^{\mathrm{a}}$, \\ Christoph Ort ${ }^{\mathrm{j}, *}$
}

a Ecole des Sciences Criminelles, University of Lausanne, Avenue Forel 15, 1015 Lausanne, Switzerland

${ }^{\mathrm{b}}$ Research Institute for Pesticides and Water, University Jaume I, Avda. Sos Baynat s/n, 12071 Castellón de la Plana, Spain

${ }^{c}$ Water and Soil Protection Laboratory, Schermenweg 11, 3014 Bern, Switzerland

d Department of Environmental Health Sciences, IRCCS-Istituto di Ricerche Farmacologiche Mario Negri, via la Masa 19, 20156 Milan, Italy

e IFT Institut für Therapieforschung, Parzivalstraße 25, 80804 Munich, Germany

${ }^{\mathrm{f}}$ Centre for Social Research on Alcohol and Drugs, SoRAD, Stockholm University, Sveavägen 160, 10691 Stockholm, Sweden

${ }^{g}$ Addiction Suisse, Avenue Louis-Ruchonnet 14, 1001 Lausanne, Switzerland

h Swiss Research Institute for Public Health and Addiction ISGF, University of Zurich, Konradstrasse 32, 8031 Zurich, Switzerland

i Jugendberatung Streetwork Stadt Zürich, Wasserwerkstrasse 17, 8006 Zurich, Switzerland

j Swiss Federal Institute of Aquatic Science and Technology (Eawag), Ueberlandstrasse 133, 8600, Dübendorf, Switzerland

\section{A R T I C L E I N F O}

\section{Article history:}

Received 19 October 2015

Received in revised form 15 January 2016

Accepted 1 February 2016

Available online $\mathrm{xxx}$

\section{Keywords:}

Illicit drugs

Epidemiology

Surveys

Crime statistics

Wastewater

\begin{abstract}
A B S T R A C T
Background: Wastewater analysis is an innovative approach that allows monitoring illicit drug use at the community level. This study focused on investigating geographical differences in drug consumption by comparing epidemiological, crime and wastewater data.

Methods: Wastewater samples were collected in 19 cities across Germany and Switzerland during one week, covering a population of approximately 8.1 million people. Self-report data and consumption offences for the investigated areas were used for comparison and to investigate differences between the indicators.

Results: Good agreement between data sources was observed for cannabis and amphetamine-type stimulants, whereas substantial discrepancies were observed for cocaine. In Germany, an important distinction could be made between Berlin, Dortmund and Munich, where cocaine and particularly amphetamine were more prevalent, and Dresden, where methamphetamine consumption was clearly predominant. Cocaine consumption was relatively homogenous in the larger urban areas of Switzerland, although prevalence and offences data suggested a more heterogeneous picture. Conversely, marked regional differences in amphetamine and methamphetamine consumption could be highlighted.

Conclusions: Combining the available data allowed for a better understanding of the geographical differences regarding prevalence, typology and amounts of substances consumed. For cannabis and amphetamine-type stimulants, the complementarity of survey, police and wastewater data could be highlighted, although notable differences could be identified when considering more stigmatised drugs (i.e. cocaine and heroin). Understanding illicit drug consumption at the national scale remains a difficult task, yet this research illustrates the added value of combining complementary data sources to obtain a more comprehensive and accurate picture of the situation.
\end{abstract}

(c) 2016 Elsevier Ireland Ltd. All rights reserved.

\footnotetext{
* Corresponding author. Ort)

E-mail addresses: frederic.been@unil.ch (F. Been), christoph.ort@eawag.ch (C.
}

\section{Introduction}

The consumption of illicit drugs in a given population or community remains a partially hidden activity that cannot be directly 
measured nor totally unveiled. Traditionally, the nature, versatility and extent of this phenomenon are assessed through the use of indicators such as consumption surveys or descriptive statistics. The last decade has seen the emergence and refinement of wastewater-based epidemiology (WBE), which relies on quantitative measurement of specific biomarkers of illicit drug use in wastewater. Presented as a complementary approach to current surveillance methods (Amundsen and Reid, 2014; Been et al., 2015; Bramness et al., 2014; Reid et al., 2012, 2011), WBE has received much attention. Although further developments will most probably refine it in the near future, WBE already enables the gathering of unique spatio-temporal information about consumption (Ort et al., 2014). Nevertheless, information about consumers (e.g. age, sex, socio-economical status and history of drug use), crucial for policy makers, cannot be gathered by this approach, but requires the use of classical monitoring tools. Yet, these are also affected by some limitations such as the difficulty to obtain representative estimates, long study times, high costs and difficulties in reaching specific groups of regular users (Banta-Green and Field, 2011; Ort et al., 2014).

In general, estimating and monitoring drug use relies on direct and indirect methods (European Monitoring Centre for Drugs and Drug Addiction; EMCDDA, 2015a). The former are mainly based on general population surveys (GPS), where a representative sample of the population is questioned about illicit drug use. The latter rely on extrapolating information about drug use from other sources indirectly related to drug use such as police statistics, treatment data as well as WBE. Despite suffering from the abovementioned limitations, these methods provide a partial, yet informative perspective of the phenomenon. By bringing together different and complementary data sources, it is expected to obtain a more precise understanding of the dynamics of illicit drug use at the national level.

In this study, samples collected from different wastewater treatment plants (WWTP) in Germany and Switzerland (including Liechtenstein) were analysed. Estimates of the average daily consumption of illicit drugs were computed based on these measurements and pharmacokinetics data available in the literature. Results obtained from wastewater analysis were compared to data derived from GPS and consumption offences registered by police forces. The aim of this study was to evaluate geographical differences and formulate hypotheses explaining divergences in the data sets. The cities investigated in the context of this study are shown in Fig. 1. Focus was set on the use of cocaine, cannabis, heroin, amphetamine, methamphetamine, and 3,4-methylenedioxymethamphetamine (MDMA or ecstasy).

\section{Materials and methods}

\subsection{Epidemiological data and police statistics}

General population survey data included the reported prevalence of use during the 12-months prior to questioning with a focus on the investigated areas (see Fig. 1 and Table 1; Kraus et al., 2015, 2014, 2010a,b, 2001; Social and Market Research Institute and Addiction Suisse, 2015). Reported substances were: cocaine, cannabis, amphetamine and amphetamine-type stimulants (ATS)-such as methamphetamine and MDMA (for Germany only) and heroin (for Switzerland only). For Germany, available data was representative of the Federal States (Bundesland; Kraus et al., 2010a,b, 2001), except for Berlin, where capture/recapture methods were used to derive the estimates (Kraus et al., 2015, 2014). For Switzerland, survey data included responses provided by participants living within the catchments of the considered WWTP
(Social and Market Research Institute and Addiction Suisse, 2015). See Supplementary material for more details about GPS data used.

Police statistics consisted of the number of offences for illicit drug use registered in the investigated areas during 2013 (Switzerland) and 2014 (Germany). Data were expressed as number of offences per year per thousand inhabitants. Epidemiological data and police statistics were not available for Liechtenstein.

\subsection{Wastewater data}

Amphetamine, methamphetamine and MDMA were quantified in wastewater samples together with the specific urinary metabolites of cocaine (i.e. benzoylecgonine), cannabis (i.e. 9carboxy-delta-9-tetrahydrocannabinol, THC-COOH) and heroin (6-monoacetylmorphine, 6-MAM).

Daily 24-h composite raw wastewater samples were collected over 7 consecutive days in March, 2014, from 19 cities (in total 22 WWTPs) across Germany and Switzerland (including Liechtenstein), as shown in Fig. 1 and Table 1. Wastewater samples were analysed using validated liquid-chromatographic tandem mass spectrometric methods. Details on the analytical procedures can be found in Bijlsma et al. (2014) (samples from Germany), Castiglioni et al. (2006) (Lugano), Been et al. (2015) (Chur, Lausanne, Lucerne, Neuchatel and Sion) and Berset et al. (2010) (Basel, Bern, Geneva, St. Gallen, Zurich, Winterthur and Liechtenstein (Bendern)). All laboratories are involved in the multi-city study published by the EMCDDA (2015b) and the analytical performance of methods used were assured by the participation in external inter-laboratory exercises.

Average daily population normalised loads (concentrations multiplied by daily wastewater flows and divided by the number of inhabitants), back-calculations (daily consumption of parent compound based on estimated loads and excretion data) and the associated errors were estimated for each city using Monte Carlo simulations, following existing procedures (Been et al., 2015; Jones et al., 2014). The parameters used are reported in Tables 2 and 3. For Berlin, the results from the four WWTPs were merged to be representative of the catchment area covering the entire city.

Nationwide estimates of illicit drug use were computed using a series of ordinary least squares and mixed effect models. The back-calculated amount of parent compound consumed in each city per day of the week was used as response variable. The number of inhabitants was used as predictor variable in ordinary regression analysis, while for mixed effect models, the day of the week was also included as (random) predictor variable. Additional information about wastewater data can be found in Supplementary material.

\section{Results}

\subsection{Population surveys}

Estimates of last-year prevalence of cocaine, cannabis and ATS in the investigated cities are shown in Figs. 2 and 3 and Table 4.

The highest prevalence for cocaine $(2.8 \%)$ was measured for Berlin, with much lower levels in the other Federal States (0.4-0.8\%). In Switzerland, Lausanne was highest (2.3\%), followed by Lucerne (1.2), Geneva (1.0\%), Zurich (0.9\%) and Winterthur $(0.9 \%)$. For cannabis, the highest prevalence in Germany were reported for Berlin (11\%) and Dortmund/Dülmen (7.3\%), with lower figures for Dresden (4.0\%) and Munich (3.5\%). In Switzerland, prevalence of cannabis use was far more homogeneous (average $7.0 \pm 2.2 \%)$, except for Sion and Lugano with very low levels (1.6\% and $3.7 \%$, respectively). Last-year prevalence data for amphetamine and ATS was available only for Germany, with the highest figures reported for Berlin and Dresden (see Fig. S1). 




Fig. 1. Cities investigated in the context of the study.

Table 1

Summary of major characteristics of the sampled WWTP and period when the considered surveys were carried out.

\begin{tabular}{|c|c|c|c|c|c|c|}
\hline Country & City/WWTP & Population $^{\mathrm{a}}$ & Typical daily flow $\left[\mathrm{m}^{3}\right.$ day $\left.^{-1}\right]$ & Sampling approach & Period & Survey \\
\hline \multirow[t]{8}{*}{ Germany } & Dortmund & 371,788 & 90,000 & NA & $12.03-18.03 .14$ & 2000 \\
\hline & Dülmen & 34,495 & 7,500 & $\mathrm{TP}$ & 12.03-18.03.14 & 2000 \\
\hline & Dresden & 593,050 & 110,000 & VP & 11.03-17.03.14 & 2009 \\
\hline & Munich & $1,000,000$ & 330,000 & $\mathrm{TP}$ & $12.03-18.03 .14$ & 2009 \\
\hline & Berlin Münchehofe $\mathrm{b}^{\mathrm{b}}$ & 290,000 & 42,000 & $\mathrm{VP}^{*}$ & $11.03-14.03 .14,17.03 .14$ & 2010-2012 \\
\hline & Berlin Ruhleben & $1,300,000$ & 210,000 & $\mathrm{VP}^{*}$ & $10.03-16.03 .14$ & \\
\hline & Berlin Schönerlinde & 750,000 & 85,000 & $\mathrm{VP}^{*}$ & 11.03-17.03.14 & \\
\hline & Berlin Wassmannsdorf & $1,500,000$ & 180,000 & $\mathrm{VP}^{*}$ & $11.03-17.03 .14$ & \\
\hline \multirow[t]{13}{*}{ Switzerland } & Basel & 260,000 & 77,000 & VP & $18.03-24-03.14$ & 2013-2014 \\
\hline & Bern & 206,655 & 65,000 & VP & 18.03-24-03.14 & 2013-2014 \\
\hline & Biel & 82,285 & $37,065.6$ & VP & $18.03-24-03.14$ & 2013-2014 \\
\hline & Chur & 52,800 & 12,000 & FP & $18.03-24-03.14$ & 2013-2014 \\
\hline & Geneva & 417,200 & 140,000 & VP & 18.03-24-03.14 & 2013-2014 \\
\hline & Lausanne & 220,000 & 108,000 & FP & $18.03-24-03.14$ & 2013-2014 \\
\hline & Lugano & 103,000 & 50,000 & $\mathrm{TP}$ & $18.03-24-03.14$ & 2013-2014 \\
\hline & Lucerne & $174^{\prime} 800$ & 75,000 & VP & $18.03-24-03.14$ & 2013-2014 \\
\hline & Neuchatel & 50,000 & 17,000 & VP & $18.03-24-03.14$ & 2013-2014 \\
\hline & Sion & 45,000 & 20,380 & $\mathrm{TP}$ & $18.03-24-03.14$ & 2013-2014 \\
\hline & St. Gallen & 52,000 & 17,800 & VP & $18.03-24-03.14$ & 2013-2014 \\
\hline & Winterthur & 125,000 & 40,000 & VP & $18.03-24-03.14$ & 2013-2014 \\
\hline & Zurich & 410,000 & 170,000 & VP & $18.03-24-03.14$ & 2013-2014 \\
\hline Liechtenstein & Bendern & 74,000 & 25,000 & $\mathrm{TP}$ & $18.03-24-03.14$ & NA \\
\hline
\end{tabular}

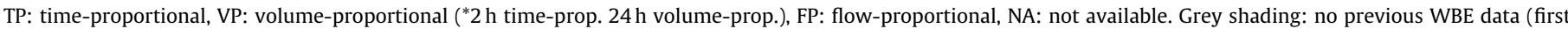
WBE data in this study).

a Reported population corresponds to figures provided by the WWTP personnel.

b No samples collected on weekend.

\subsection{Police statistics}

Reported consumption offences per thousand inhabitants in German and Swiss cities are illustrated in Figs. 2-5 and Table 4. Highest rates for cocaine in Germany were reported in Dortmund
(0.42), followed by Munich (0.29) and Berlin (0.22). Particularly low offence rates were reported in Dresden and Dülmen. In Switzerland, highest rates were reported in Bern (5.9), Lausanne (3.6) and Biel (3.0). Heroin-related data was only available for Switzerland, where it depicted a situation similar to cocaine (see Fig. S2). For cannabis,

Please cite this article in press as: Been, F., et al., Assessing geographical differences in illicit drug consumption-A comparison of results from epidemiological and wastewater data in Germany and Switzerland. Drug Alcohol Depend. (2016), http://dx.doi.org/10.1016/j.drugalcdep.2016.02.002 
Table 2

General parameters used in Monte Carlo simulations to estimate daily mass loads [ $\mathrm{g} \mathrm{day}^{-1}$ ] of illicit drugs and their metabolites.

\begin{tabular}{|c|c|c|c|c|}
\hline & $\mu$ & SE & Distribution & Note \\
\hline Flow & Daily flow [L day ${ }^{-1}$ ] & $20 \%$ of daily flow & $\begin{array}{l}\text { Normal } \\
\left(\mu, \mathrm{SE}^{2}\right)\end{array}$ & $\begin{array}{l}\text { Based on findings by Ort et al. } \\
\text { ( } 2010 \text { a,b), the error associated to daily } \\
\text { flow measurements (S.E.) was } \\
\text { estimated as } 20 \% \text { of the total daily flow. }\end{array}$ \\
\hline $\begin{array}{l}\text { Substance } \\
\text { concentration }\end{array}$ & $\begin{array}{l}\text { Measured } \\
\text { concentration } \\
{\left[\mathrm{ng} \mathrm{L}^{-1}\right]}\end{array}$ & $\begin{array}{l}25 \% \text { of measured } \\
\text { concentration }\end{array}$ & $\begin{array}{l}\text { Normal } \\
\left(\mu, \mathrm{SE}^{2}\right)\end{array}$ & $\begin{array}{l}\text { From a preliminary evaluation of an } \\
\text { inter-laboratory test, an average } \\
\text { deviation of } 25 \% \text { from the expected } \\
\text { values was reported by the } \\
\text { participating laboratories }\end{array}$ \\
\hline
\end{tabular}

$\mu=$ mean, $\mathrm{SE}=$ standard error.

Table 3

Compound specific parameters used in Monte Carlo simulations to back-calculate the amounts of parent compound initially consumed.

\begin{tabular}{|c|c|c|c|c|c|}
\hline & Substance & $\mu$ & SE & Distribution & Note \\
\hline \multirow[t]{4}{*}{ Excretion rates } & Benzoylecgonine & $30.58 \%$ & $3.35 \%$ & \multirow[t]{4}{*}{$\operatorname{Beta}(a, b)$} & \multirow{4}{*}{$\begin{array}{l}\text { Inverse-variance weighted } \\
\text { average. Data derived from } \\
\text { summary in Khan and Nicell } \\
(2012,2011)\end{array}$} \\
\hline & MDMA & $15.78 \%$ & $1.83 \%$ & & \\
\hline & Amphetamine & $29.12 \%$ & $0.93 \%$ & & \\
\hline & Methamphetamine & $28.56 \%$ & $2.59 \%$ & & \\
\hline
\end{tabular}

$\mu=$ mean, $\mathrm{SE}=$ standard error.

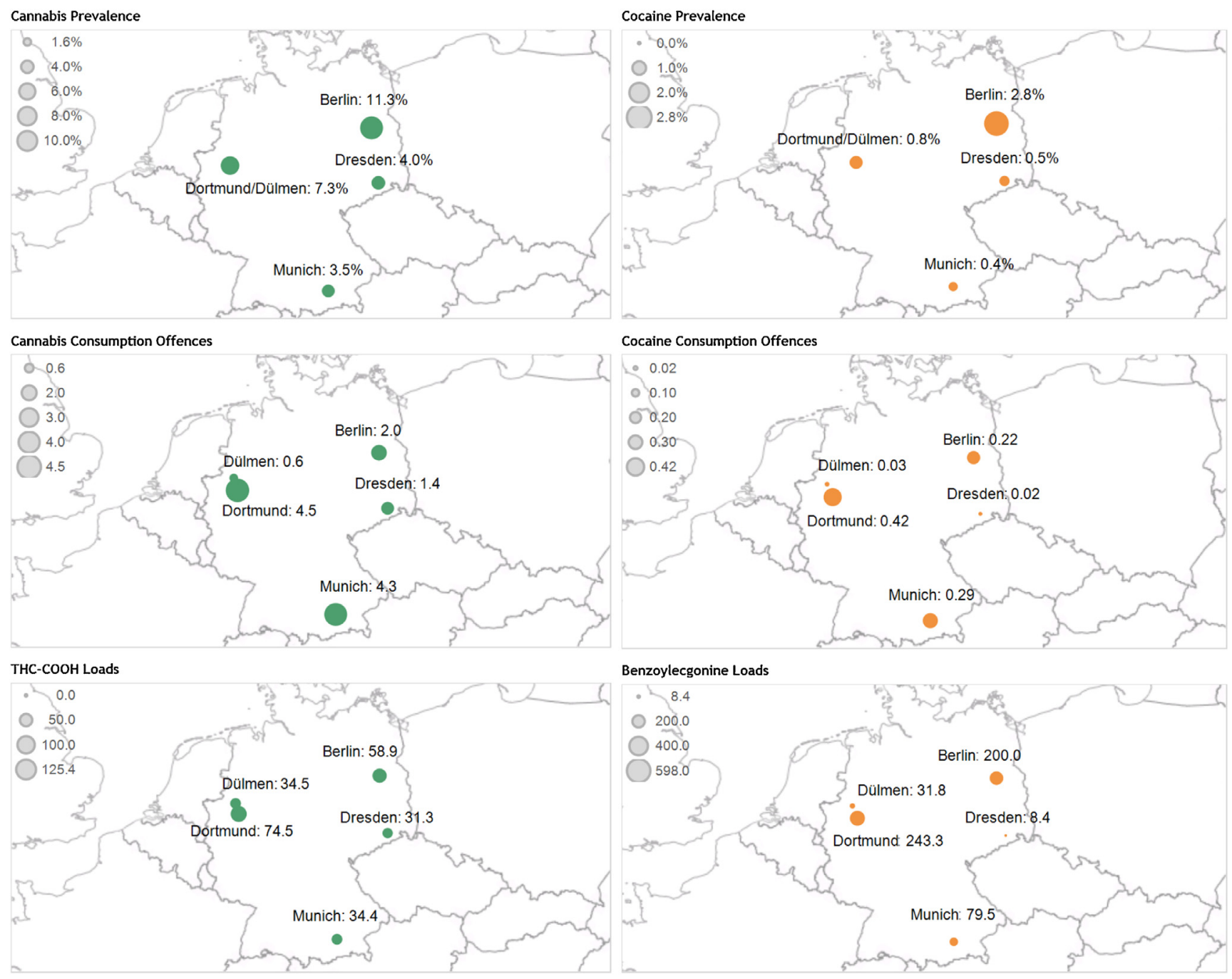

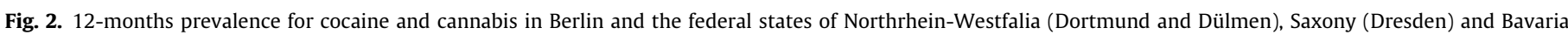

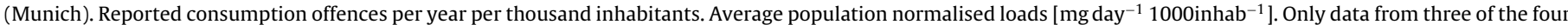
WWTP sampled in Berlin are reported (weekend data were missing for Berlin-Münchehofe).

Please cite this article in press as: Been, F., et al., Assessing geographical differences in illicit drug consumption-A comparison of results from epidemiological and wastewater data in Germany and Switzerland. Drug Alcohol Depend. (2016), http://dx.doi.org/10.1016/j.drugalcdep.2016.02.002 

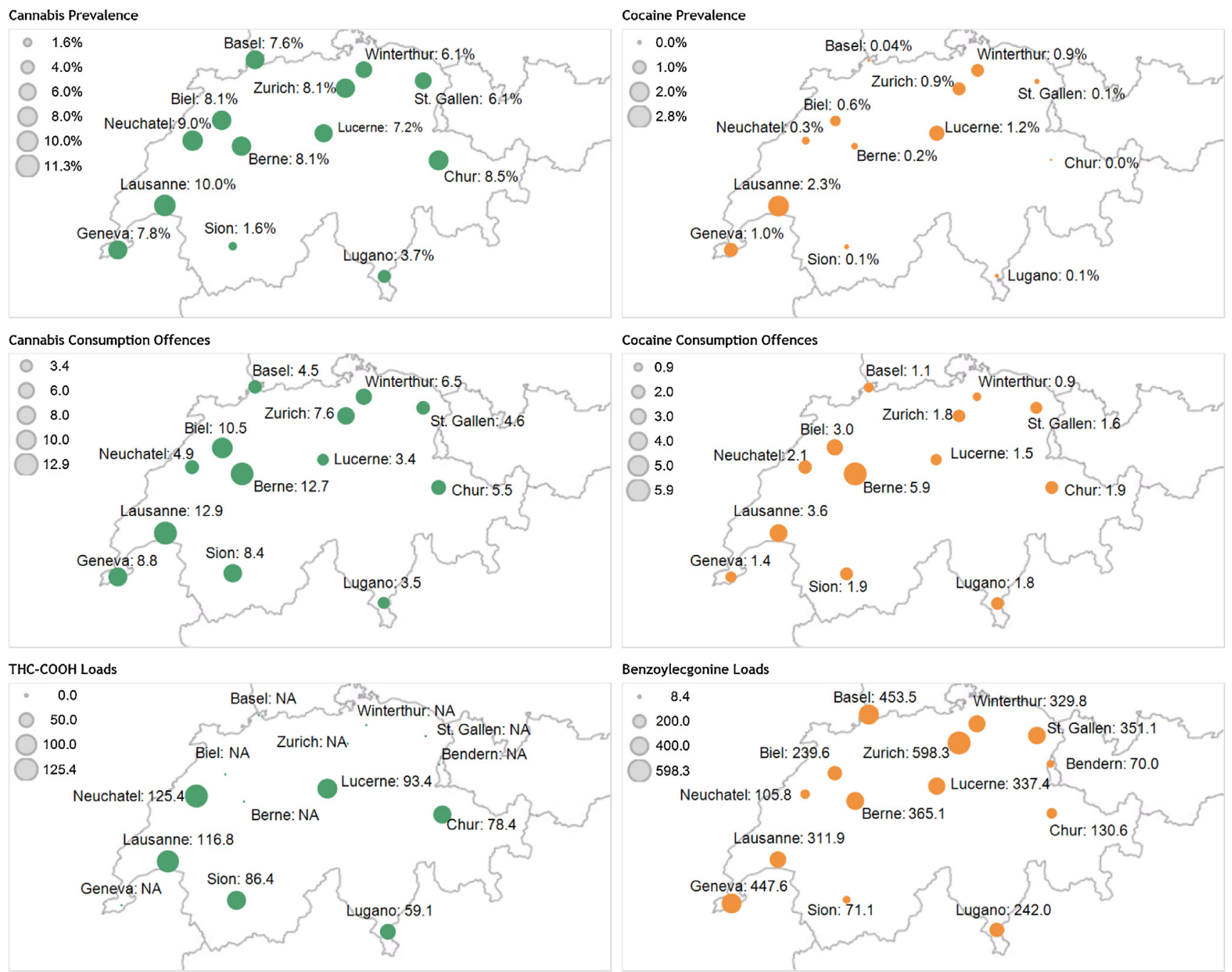

\section{Benzoylecgonine Loads}

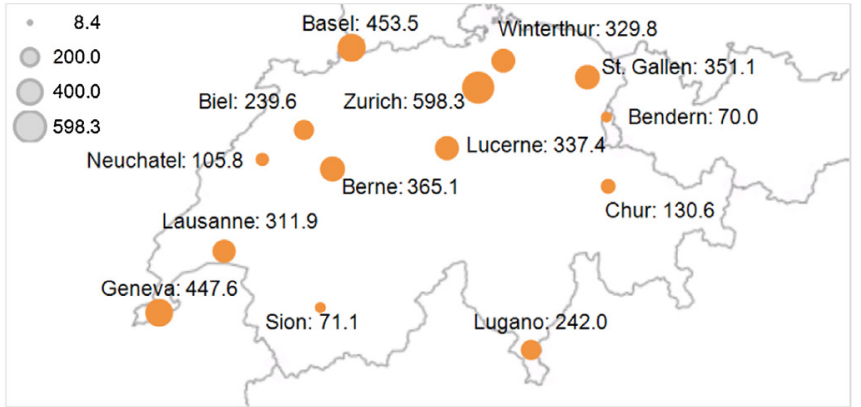

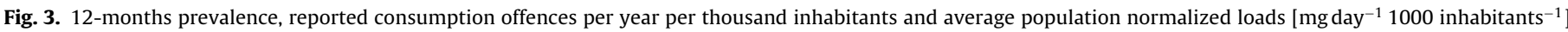

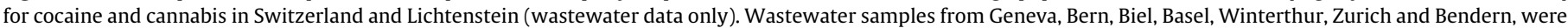
not analysed for THC-COOH.

highest rates were reported in Munich and Dortmund (4.3 and 4.5, respectively), with the remaining cities ranging between 0.6 and 2 . Slightly higher cannabis-related offences were reported in western Switzerland (between 8.4 and 13), compared to the eastern and southern parts (between 3.4 and 7.6). Data about MDMA-related offences was available only for Switzerland, where it showed a heterogeneous situation. Amphetamine offences were quite homogeneous in the northern cities of Germany (range 0.25-0.5), while the highest rate was reported in Munich (0.72). In Switzerland, there was a clear difference between south/west and north/east, with the former reporting lower rates $(0-0.25)$ compared to the latter (0.2-0.65). For methamphetamine, the number of offences was generally low in the German cities (0-0.11), except for Dresden which reported offence rates of 0.95. In Switzerland, low rates were reported (0-0.06), except for Neuchatel, Biel and St. Gallen, where these were substantially higher (0.15-0.73).

\subsection{Wastewater data}

3.3.1. Illicit drug loads. Population normalised loads of target substances measured in WWTP in Germany, Switzerland and Liechtenstein are reported in Figs. 2-5 and Table 4. Fluctuations in drug loads observed during the week are illustrated in Figs. S3 and S4. Weekend samples for the WWTP of Berlin Münchenhofe were not available, thus, results refer only to the WWTP of Berlin Ruhleben, Schönerlinde and Wassmannsdorf. The contribution of drug loads measured during the week in Münchenhofe was, however, limited (i.e. only $3.3 \%$ of the total), except for amphetamine which was in the same order of magnitude as the other WWTPs.

Amongst German cities, highest benzoylecgonine loads were measured in Dortmund and Berlin (243.3 and $200 \mathrm{mg} \mathrm{day}^{-1} 1000$ inhab $^{-1}$ ). In Switzerland, highest per capita loads were measured in Zurich, followed by Basel and Geneva (598.2, 453.4 and $447.6 \mathrm{mg} \mathrm{day}^{-1} 1000$ inhab $^{-1}$, respectively). Lowest loads were measured in Bendern (LI) and Sion (approximately $70 \mathrm{mg} \mathrm{day}^{-1} 1000$ inhab $^{-1}$ ).

For THC-COOH, a more homogeneous picture was obtained both in Germany and Switzerland. Nonetheless, Dortmund and Berlin still exhibited twice as high per-capita loads compared to the other German cities (74.5 and 58.9 versus approximately $30 \mathrm{mg} \mathrm{day}^{-1} 1000 \mathrm{inhab}^{-1}$ ). In Switzerland, loads ranged from 59 in Lugano to $125 \mathrm{mg} \mathrm{day}^{-1} 1000$ inhab $^{-1}$ in Neuchatel.

In Germany, highest MDMA loads were measured in Berlin, followed by Munich, Dortmund and Dülmen (29.5, 18.0, 10.7 and $9.5 \mathrm{mg} \mathrm{day}^{-1} 1000 \mathrm{inhab}^{-1}$ respectively). In Switzerland, loads

Please cite this article in press as: Been, F., et al., Assessing geographical differences in illicit drug consumption-A comparison of results from epidemiological and wastewater data in Germany and Switzerland. Drug Alcohol Depend. (2016), http://dx.doi.org/10.1016/j.drugalcdep.2016.02.002 


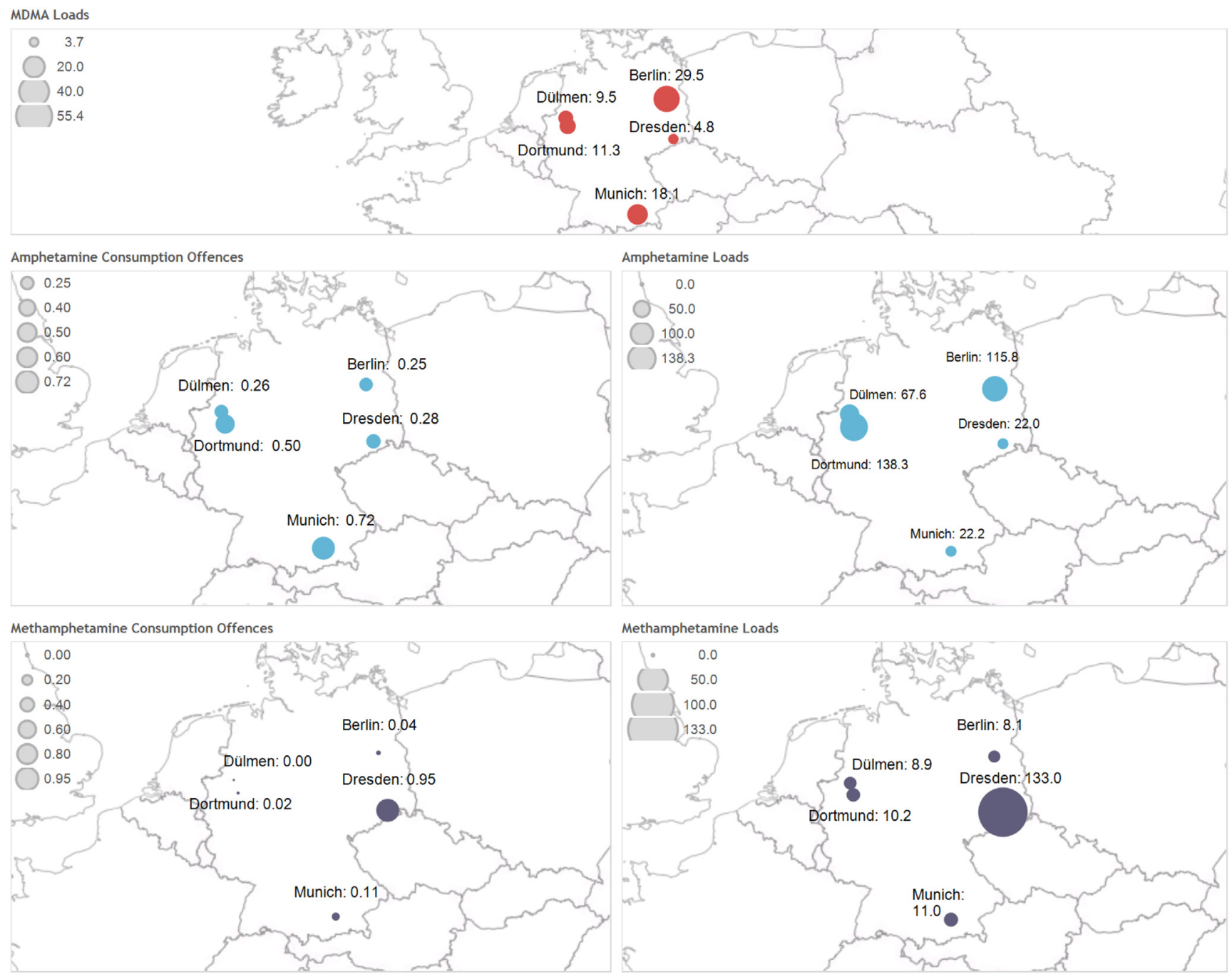


year per thousand inhabitants in Germany. Offences data for MDMA was not available.

ranged from 55.4 in Zurich to $3.7 \mathrm{mg} \mathrm{day}^{-1} 1000 \mathrm{inhab}^{-1}$ in Lugano. In Bendern (LI), $3.6 \mathrm{mg} \mathrm{day}^{-1} 1000$ inhab $^{-1}$ were measured.

Consumption of amphetamine seemed to be mainly localised in the cities of Berlin, Dortmund and Dülmen (ranging from 67.6 to $138.3 \mathrm{mg} \mathrm{day}^{-1} 1000 \mathrm{inhab}^{-1}$ ). In Switzerland, amphetamine was predominant in the north-eastern part of the country $\left(8.9-25.6 \mathrm{mg} \mathrm{day}^{-1} 1000\right.$ inhab $\left.^{-1}\right)$, while its occurrence was less marked in western and southern parts of the country (0-10.5 $\left.\mathrm{mg} \mathrm{day}^{-1} 1000 \mathrm{inhab}^{-1}\right)$. Bendern (Liechtenstein) showed results similar to western Switzerland ( $5.7 \mathrm{mg} \mathrm{day}^{-1} 1000 \mathrm{inhab}^{-1}$ ).

Highest methamphetamine loads were measured in Dresden (133 $\mathrm{mg} \mathrm{day}^{-1} 1000 \mathrm{inhab}^{-1}$ ). In Switzerland, consumption seemed to be mainly localized in the cities of Neuchatel, Zurich and Biel (33.4, 21.8 and $19.1 \mathrm{mg} \mathrm{day}^{-1} 1000 \mathrm{inhab}^{-1}$, respectively).

Occurrence of 6-MAM (exclusive metabolite of heroin) was monitored only in Switzerland, as shown in Fig. S4. Highest loads were measured in the cities of Zurich, Winterthur and St. Gallen (17.7, 13.5 and $12.1 \mathrm{mg} \mathrm{day}^{-1} 1000 \mathrm{inhab}^{-1}$, respectively), while other large cities (>100,000 inhabitants) were characterised by similar loads (between 6.7 and $10.9 \mathrm{mg} \mathrm{day}^{-1} 1000 \mathrm{inhab}^{-1}$ ). In smaller catchments, substantially lower per capita loads were measured (between 1.9 and $2.7 \mathrm{mg}_{\text {day }}{ }^{-1} 1000 \mathrm{inhab}^{-1}$ ), except for Biel which was in the same range as larger urban areas. No 6-MAM was detected in Bendern.
3.3.2. Consumption estimates. Using measured loads and excretion data reported in Table 3, the amounts of pure substance (i.e. parent compound) initially consumed were back-calculated using Monte Carlo simulations. Results are reported in Table 5.

Nationwide consumption estimates are given only for Switzerland as the size of the population sampled during the campaign corresponds to approximately $27 \%$ of the total Swiss population (sampled population: 2.2 million, total population in 2013: 8.14; Swiss Federal Statistical Office, 2014). Furthermore, estimates were limited to cocaine and MDMA as these are the only two substances detected in all cities. Scatterplots of consumption estimates as a function of the population are illustrated in Fig. 6 . Prior to regression analysis, data was log-transformed to correct for heteroscedasticity (i.e. unequal variances between observations).

For cocaine, a mixed effect model was used to extrapolate both, the daily average and weekly consumption estimate for municipalities not included in the wastewater sampling campaign (see Supporting material, Fig. S5 and Table S1 for further details). As reported in Table 6 , the nationwide average daily consumption of cocaine was estimated to approximately $8.8 \mathrm{~kg}$ of pure substance. In terms of weekly consumption, this was estimated to $61.6 \mathrm{~kg}$ of pure cocaine.

For MDMA, mixed effect models did not provide satisfactory results, thus, an ordinary least squares model was used to 

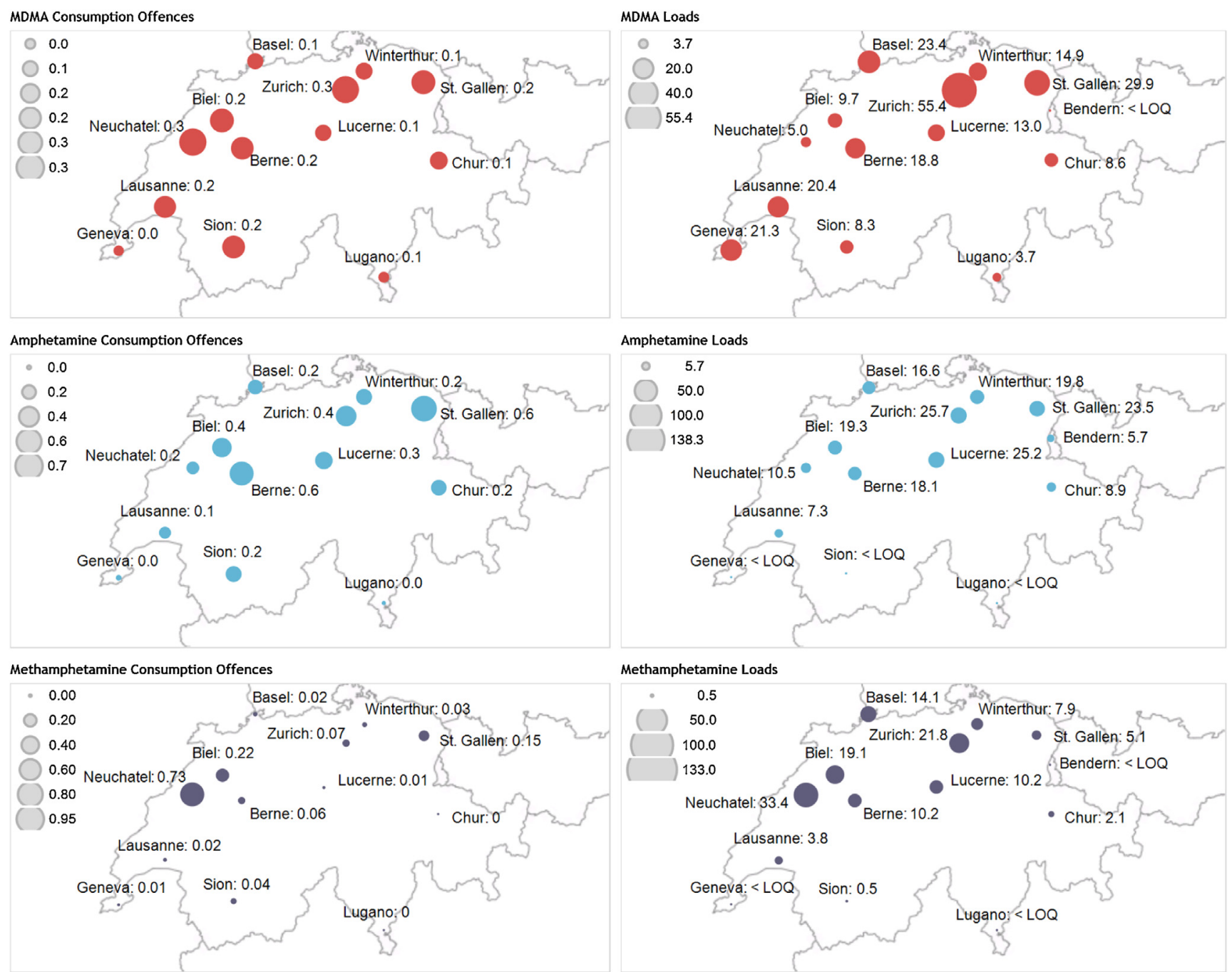

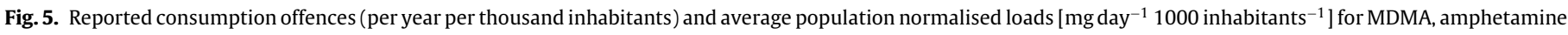
and methamphetamine measured in Switzerland and Liechtenstein.

extrapolate the nationwide daily average consumption which was estimated at $0.367 \mathrm{~kg} \mathrm{day}^{-1}$ of pure MDMA (as reported in Table 6).

\section{Discussion}

\subsection{Cocaine}

In Germany, the overlap observed between prevalence, offences and wastewater data suggests that cocaine consumption is predominant in the cities of Dortmund and Berlin, although lower prevalence was reported in Dortmund. This difference, however, may be due to methodological differences between survey estimates in Dortmund (and other German cities) and capture/recapture estimates as applied in Berlin. Firstly, capture/recapture methods are less likely to produce underestimates, and secondly, the survey estimates used apply to regions (Bundesland) rather than to cities. For the city of Munich, offence data suggest a high occurrence of cocaine use, yet both prevalence and wastewater data indicate the contrary. In the case of Dresden, offence and wastewater data suggest limited cocaine consumption, whilst survey data indicate that prevalence is similar to Munich and Dortmund.

In Switzerland, conventional indicators depicted a highly heterogeneous situation, in particular between larger urban areas (i.e. $>100,000$ inhabitants), which showed substantial differences in prevalence and number of reported offences. Yet, these were less pronounced when observing results from wastewater analysis. Possible explanations for these discrepancies are reporting bias, concealment, stigmatization, city size, drug availability, as well as law enforcement activities, all of which strongly influence survey outcomes and offence rates. Still, an overlap between data sources was observed for urban areas with less than 100,000 inhabitants.

According to prevalence data, there is a slightly higher cocaine consumption in Swiss compared to German cities, which is confirmed by wastewater analysis. This is in contradiction with nationwide figures, which suggest that last-year prevalence is higher in Germany compared to Switzerland (i.e. 0.8 and $0.5 \%$, respectively (Gmel et al., 2014; Pabst et al., 2013)). Yet, the small number of cities analysed in Germany limits the interpretation. Results from the analysis of benzoylecgonine were consistent with findings from the multi-city study reported by the EMCDDA (2015b) and Ort et al. (2014).

\subsection{Cannabis}

Overall, prevalence and wastewater data showed a similar picture for cannabis consumption in Germany, while offence rates diverged slightly from the former indicators. Highest prevalence 
Table 4

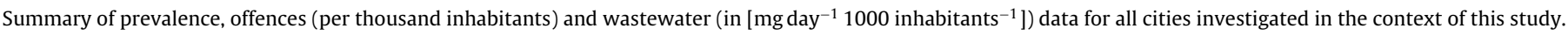

\begin{tabular}{|c|c|c|c|c|c|c|c|c|c|c|}
\hline \multirow[t]{2}{*}{ City } & \multicolumn{4}{|c|}{ Cocaine } & \multicolumn{3}{|c|}{ Cannabis } & \multicolumn{3}{|l|}{ MDMA } \\
\hline & \multicolumn{2}{|c|}{ Prevalence } & Offences & Wastewater ${ }^{\mathrm{a}}$ & Survey & Offences & Wastewater & Survey & Offences & Wastewater \\
\hline Basel & \multicolumn{2}{|l|}{$0.04 \%$} & 1.13 & 453.5 & $7.6 \%$ & 4.52 & - & - & 0.1 & 23.4 \\
\hline Berne & \multicolumn{2}{|l|}{$0.2 \%$} & 5.93 & 365.1 & $8.1 \%$ & 12.68 & - & - & 0.2 & 18.8 \\
\hline Biel & \multicolumn{2}{|l|}{$0.6 \%$} & 3.01 & 239.6 & $8.1 \%$ & 10.53 & - & - & 0.2 & 9.7 \\
\hline Chur & \multicolumn{2}{|l|}{$0 \%$} & 1.91 & 130.6 & $8.5 \%$ & 5.46 & 78.4 & - & 0.1 & 8.6 \\
\hline Geneva & \multicolumn{2}{|l|}{$1.0 \%$} & 1.42 & 447.6 & $7.8 \%$ & 8.77 & - & - & 0 & 21.3 \\
\hline Lausanne & \multicolumn{2}{|l|}{$2.3 \%$} & 3.58 & 311.9 & $10.0 \%$ & 12.95 & 116.8 & - & 0.2 & 20.4 \\
\hline Lugano & \multicolumn{2}{|l|}{$0.1 \%$} & 1.81 & 242.0 & $3.7 \%$ & 3.54 & 59.1 & - & 0.1 & 3.7 \\
\hline Lucerne & \multicolumn{2}{|l|}{$1.2 \%$} & 1.46 & 337.4 & $7.2 \%$ & 3.37 & 93.4 & - & 0.1 & 13.0 \\
\hline Neuchatel & \multicolumn{2}{|l|}{$0.3 \%$} & 2.06 & 105.8 & $9.0 \%$ & 4.86 & 125.4 & - & 0.3 & 5.0 \\
\hline Sion & $0.1 \%$ & & 1.87 & 71.1 & $1.6 \%$ & 8.44 & 86.4 & - & 0.2 & 8.3 \\
\hline St. Gallen & $0.1 \%$ & & 1.64 & 351.1 & $6.1 \%$ & 4.64 & - & - & 0.2 & 29.9 \\
\hline Winterthur & $0.9 \%$ & & 0.85 & 329.8 & $6.1 \%$ & 6.51 & - & - & 0.1 & 14.9 \\
\hline Zurich & $0.9 \%$ & & 1.79 & 598.3 & $8.1 \%$ & 7.60 & - & - & 0.3 & 55.4 \\
\hline Bendern & - & & - & 70.0 & - & - & - & - & - & $<\mathrm{LOQ}$ \\
\hline Dortmund & $0.8 \%$ & & 0.42 & 243.3 & $7.3 \%$ & 4.53 & 74.5 & - & - & 11.3 \\
\hline Dülmen & - & & 0.03 & 31.8 & & 0.64 & 34.5 & - & - & 9.5 \\
\hline Dresden & $0.5 \%$ & & 0.02 & 8.4 & $4.0 \%$ & 1.36 & 31.3 & - & - & 4.8 \\
\hline Munich & $0.4 \%$ & & 0.29 & 79.5 & $3.5 \%$ & 4.28 & 34.4 & - & - & 18.1 \\
\hline Berlin & $2.8 \%$ & & 0.22 & 200.0 & $11.3 \%$ & 2.00 & 58.9 & - & - & 29.5 \\
\hline City & & Amphetar & mine & & Metl & phetamine & & & Heroin & \\
\hline & & Offences & & Wastewater & Offe & & Wastewater & & Offences & Wastewater $^{\mathrm{b}}$ \\
\hline Basel & & 0.21 & & 16.6 & 0.02 & & 14.1 & & 0.63 & 7.4 \\
\hline Berne & & 0.55 & & 18.1 & 0.06 & & 10.2 & & 5.65 & 7.9 \\
\hline Biel & & 0.37 & & 19.3 & 0.22 & & 19.1 & & 3.57 & 8.8 \\
\hline Chur & & 0.24 & & 8.9 & 0 & & 2.1 & & 1.14 & $<$ LOQ \\
\hline Geneva & & 0.03 & & $<\mathrm{LOQ}$ & 0.01 & & $<\mathrm{LOQ}$ & & 1.73 & 9.6 \\
\hline Lausanne & & 0.14 & & 7.3 & 0.02 & & 3.8 & & 3.57 & 7.2 \\
\hline Lugano & & 0.02 & & $<\mathrm{LOQ}$ & 0 & & $<\mathrm{LOQ}$ & & 0.41 & 6.7 \\
\hline Lucerne & & 0.30 & & 25.2 & 0.01 & & 10.2 & & 0.82 & 7.1 \\
\hline Neuchatel & & 0.16 & & 10.5 & 0.73 & & 33.4 & & 0.67 & $<\mathrm{LOQ}$ \\
\hline Sion & & 0.25 & & $<\mathrm{LOQ}$ & 0.04 & & 0.5 & & 0.62 & 1.9 \\
\hline St. Gallen & & 0.64 & & 23.5 & 0.15 & & 5.1 & & 3.03 & 8.8 \\
\hline Winterthur & & 0.25 & & 19.8 & 0.03 & & 7.9 & & 0.86 & 13.4 \\
\hline Zurich & & 0.41 & & 25.7 & 0.07 & & 21.8 & & 0.64 & 17.7 \\
\hline Bendern & & - & & 5.7 & - & & $<$ LOQ & & & $<$ LOQ \\
\hline Dortmund & & 0.50 & & 138.3 & 0.02 & & 10.2 & & - & - \\
\hline Dülmen & & 0.26 & & 67.6 & 0.00 & & 8.9 & & - & - \\
\hline Dresden & & 0.28 & & 22.0 & 0.95 & & 133.0 & & - & - \\
\hline Munich & & 0.72 & & 22.2 & 0.11 & & 11.0 & & - & - \\
\hline Berlin & & 0.25 & & 115.8 & 0.04 & & 8.1 & & - & - \\
\hline
\end{tabular}

a Population normalised loads of benzoylecgonine, the major metabolite of cocaine.

b Population normalised loads of 6-monoacetylmorphine, the exclusive metabolite of heroin.

was reported for Berlin and Dortmund, with the latter having also the highest THC-COOH per capita loads. This could be due to its proximity to the Netherlands, where a more liberal drug policy on cannabis use is in force (Bijlsma et al., 2012; Thomas et al., 2012). Yet, no statistical difference in the measured loads could be found between Berlin and Dortmund (Wilcox Rank Sum $p$ value $>\alpha=0.05$ ). Similarly to cocaine, higher offence rates were reported in Munich, while both prevalence and wastewater data suggested that these were substantially lower than in Berlin and Dortmund.

Based on prevalence and wastewater data, cannabis consumption appears quite uniform across the investigated areas, except for the city of Sion where reported prevalence was particularly low compared to offence and wastewater results. In general, offence rates are more heterogeneous compared to the other two indicators. However, it should be noted that since October 1 2013, use of cannabis by adults has been decriminalised and can now be punished with an administrative fine, without being recorded as a criminal offence (Federal Council, 2013).

Comparisons between the two countries suggest that cannabis consumption is slightly higher in Switzerland, which is in agree- ment with national prevalence figures (i.e. 12-months prevalence of $4.5 \%$ and $5 \%$ in Germany and Switzerland, respectively; Gmel et al., 2014; Pabst et al., 2013).

Results from wastewater analysis obtained in this context were consistent with findings from the multi-city study reported by the EMCDDA (2015b) and Ort et al. (2014).

\subsection{Amphetamine-type stimulants}

The available indicators suggest that methamphetamine consumption in Germany was predominant in Dresden, while amphetamine consumption was substantially lower compared to the others cities. The occurrence of methamphetamine in Dresden is known to be related to its proximity to the Czech Republic, an important methamphetamine producer (EMCDDA, 2015c). Interestingly, available data suggests that consumption of methamphetamine is limited elsewhere, including Berlin and Munich, which are both in the eastern part of the country and thus, potentially affected by imports of methamphetamine from the Czech Republic. However, this is in agreement with the supposedly smallscale production (i.e. kitchen laboratories), whose outputs are 
Table 5

7-day back-calculated average illicit drug consumption [g day $\left.{ }^{-1}\right]$ (standard error).

\begin{tabular}{|c|c|c|c|c|c|}
\hline & Population & Cocaine (benzolyecgonine) & MDMA & Amphetamine & Methamphetamine \\
\hline Dortmund & 371,788 & $313.2(120.5)$ & $26.8(11.2)$ & $176.9(65.6)$ & $13.4(5)$ \\
\hline Dülmen & 34,495 & $3.8(1.6)$ & $2.1(0.9)$ & $8(3)$ & $1.1(0.4)$ \\
\hline Dresden & 593,050 & $17.2(6.6)$ & $18.1(7.9)$ & $44.9(17.1)$ & $278.2(104.1)$ \\
\hline Munich & $1,000,000$ & $274.9(115.4)$ & $115.8(51.3)$ & $76.4(30.3)$ & $38.8(14.4)$ \\
\hline Berlin $^{\mathrm{a}}$ & $3,550,000$ & $2456.9(597.1)$ & $672.4(172.2)$ & $1413.8(305.7)$ & $102.1(102.1)$ \\
\hline Berlin $^{\mathrm{b}}$ & $3,840,000$ & $2212.1(572.6)$ & $690.1(690.1)$ & $1374.6(310.7)$ & $100.7(26.4)$ \\
\hline Basel & 260,000 & $408.1(155.8)$ & $38.9(17.3)$ & $14.8(5.8)$ & $13(4.8)$ \\
\hline Bern & 206,655 & $261.2(98.7)$ & $25(12.1)$ & $12.9(4.7)$ & $7.5(2.9)$ \\
\hline Biel & 82,285 & $68.3(26.2)$ & $5.1(2.3)$ & $5.5(2)$ & $5.5(2.3)$ \\
\hline Chur & 52,800 & $23.9(9.3)$ & $2.9(1.3)$ & $1.6(0.6)$ & $0.4(0.2)$ \\
\hline Geneva & 417,200 & $646.4(247.9)$ & $56.9(26.3)$ & $6.8(2.6)$ & $4.5(1.8)$ \\
\hline Lausanne & 220,000 & 237.5 (91.9) & $28.8(13.7)$ & $5.5(2.1)$ & $3(1.2)$ \\
\hline Lugano & 103,000 & $86.2(32.8)$ & $2.4(1)$ & $1.4(0.5)$ & $0.2(0.1)$ \\
\hline Lucerne & 174,800 & $204.1(81.5)$ & $14.6(6.9)$ & $15.1(5.7)$ & $6.3(2.4)$ \\
\hline Neuchatel & 50,000 & $18.3(7.1)$ & $1.6(0.8)$ & $1.8(0.7)$ & $5.9(2.3)$ \\
\hline Sion & 45,000 & $11.1(4.2)$ & $2.4(1.2)$ & $0(0)$ & $0.1(0.1)$ \\
\hline St. Gallen & 52,000 & $63.2(24.4)$ & $10(4.4)$ & $4.2(1.8)$ & $0.9(0.4)$ \\
\hline Winterthur & 125,000 & $142.7(55.6)$ & $11.9(5.2)$ & $8.5(3.1)$ & $3.5(1.4)$ \\
\hline Zurich & 410,000 & $849(330.6)$ & $145.7(77.2)$ & $36.2(14.6)$ & $31.5(11.8)$ \\
\hline Bendern (Li) & 74,000 & 17.9 (6.9) & $1.7(0.7)$ & $1.5(0.6)$ & $0.6(0.2)$ \\
\hline
\end{tabular}

a 7-day average calculated from three out four WWTP in Berlin (weekend included).

b 5-day average calculated from the four WWTP in Berlin (weekend excluded).

\section{Table 6}

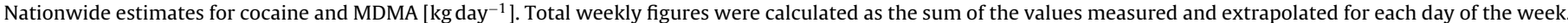
For MDMA this was not possible and an ordinary least squares regression was used, which does not allow extrapolating day-by-day consumption estimates.

\begin{tabular}{|c|c|c|c|c|}
\hline & & Cocaine (BE) $\left[\mathrm{kg} \mathrm{day}^{-1}\right]$ & MDMA $\left[\mathrm{kg} \mathrm{day}^{-1}\right]$ & Considered population \\
\hline \multirow{4}{*}{$\begin{array}{l}\text { Measured } \\
\text { (wastew- } \\
\text { a- } \\
\text { Extryapolated }\end{array}$} & 7-day average & 3.0 & 0.346 & \multirow[t]{2}{*}{$2,198,740$} \\
\hline & Weekly & 21.2 & 2.4 & \\
\hline & 7-day average & 5.8 & 0.023 & \multirow[t]{2}{*}{$5,793,612$} \\
\hline & Weekly & 40.4 & - & \\
\hline \multirow[t]{2}{*}{ Total } & 7-day average & 8.8 & 0.367 & \multirow[t]{2}{*}{$7,992,352$} \\
\hline & Weekly & 61.6 & - & \\
\hline
\end{tabular}

thought to supply predominantly domestic and neighbouring markets (EMCDDA, 2014). Despite recent signs that methamphetamine consumption is spreading (EMCDDA, 2015d), our data suggest that its consumption is still limited to border areas.

The proximity of Dortmund to the Netherlands, which is known for its ATS production (EMCDDA, 2015d, 2014), does not seem to have an effect on the availability and consumption of these substances. In fact, amphetamine loads were in the same range as those measured in Berlin and MDMA loads were below values measured in Munich. Whilst comparisons with prevalence data should be interpreted carefully, as these do not distinguish between the type of ATS reported, our results confirm the more widespread use of amphetamine compared to methamphetamine (EMCDDA, 2015d, 2014). Similar findings were obtained in a recent study where wastewater samples from various cities in western Germany were analysed (Meyer et al., 2015).

Catchment specific prevalence data on ATS was not available for Switzerland, yet offence rates and wastewater data for both MDMA and amphetamine showed similar patterns. The occurrence of MDMA seems to be predominant in larger urban areas, while smaller cities are generally less affected. For amphetamine, both data sources suggest higher prevalence rates in the north-eastern part of Switzerland. Offences related to methamphetamine use were highest in Neuchatel, Biel and St. Gallen. Wastewater analysis confirms these findings, except for St. Gallen where substantially lower loads were measured. Similarly to amphetamine use, methamphetamine consumption appears to be more widespread in the northern part of the country.

In both countries, highest MDMA loads were measured in the largest cities, Berlin and Zurich, with the latter having the overall highest figures. Measurements in Munich were similar to those recorded in other larger urban areas (i.e. >100,000 inhabitants) in Switzerland, while Dortmund and Dülmen showed loads similar to smaller cities in Switzerland. Amphetamine consumption was clearly more prevalent in the northern part of Germany. This is in agreement with national figures which suggest that its consumption is higher in Germany (12-months prevalence: $0.7 \%$ for ATS (Pabst et al., 2013)) compared to Switzerland (12-months prevalence: $0.4 \%$ for amphetamine and $0 \%$ for methamphetamine (Gmel et al., 2014)). In the case of methamphetamine, available data indicate that consumption is centred in some "hotspots", while other areas included in this study are less affected.

Results from wastewater analysis obtained in this context were in line with the multi-city study reported by the EMCDDA (EMCDDA, 2015b; Ort et al., 2014).

\subsection{Heroin}

The highest offence rates were reported in Lausanne, Bern and Biel, while the highest 6-MAM loads were measured in Zurich and Winterthur. Except for the latter two cities, the picture drawn from wastewater analysis suggests that heroin consumption is quite uniform throughout the country. In agreement with reported offences, Sion and Chur were the cities with the lowest per capita loads. There is evidence that the number of people being apprehended for consumption of highly stigmatized drugs is likely influenced by law enforcement strategies, in particular for heavy opiate users. Thus, classical surveillance systems provide a biased picture of the situation, rendering comparisons difficult. 

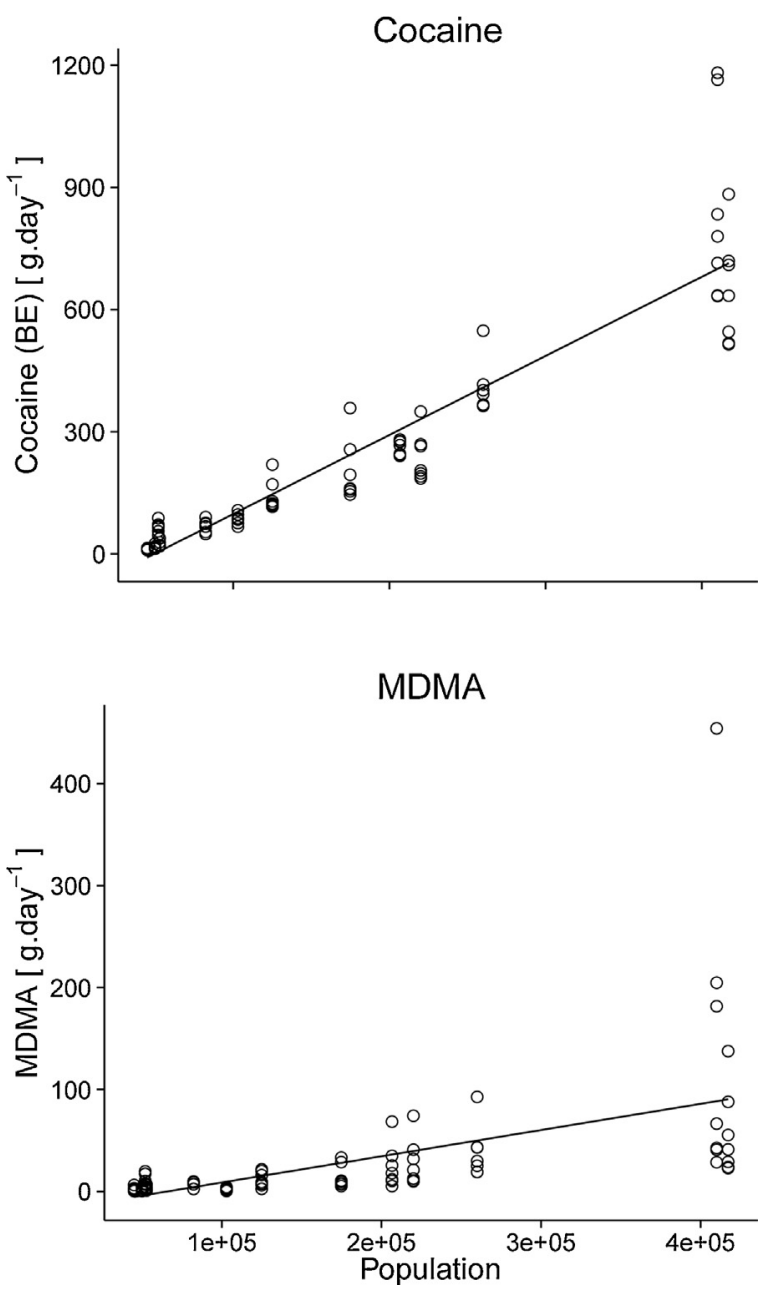

Fig. 6. Scatter plot of estimated cocaine (based on benzoylecgonine loads) and MDMA consumption as a function of the size of the population. Line: ordinary least square.

\subsection{Consumption estimates}

Consumption estimates for each substance and city included in the sampling frame are reported in Table 5. Whilst these figures are affected by various uncertainties, and should thus be interpreted carefully, they provide a rough idea of the amounts of substances consumed in the investigated areas. As previously discussed, amphetamine seems to be the predominant stimulant drug in Germany, while cocaine seems to be more widespread in Switzerland. Data for Liechtenstein suggest that cocaine is the main stimulant, with levels of use comparable to cities of similar size in Switzerland.

Nationwide consumption estimates for cocaine and MDMA for Switzerland derive from data collected only in larger urban areas over the course of one week. These estimates may thus not correspond to consumption in smaller catchments not included in the study (i.e. less than 40,000 inhabitants), nor may they be representative of consumption throughout the year. Moreover, the excretion rates used for the calculations, which derive from pharmacological studies with a limited number of participants, and the potential degradation of biomarkers in sewers, might further affect the accuracy of the estimates. Nonetheless, these rough estimates allow assessing the order of magnitude of quantities consumed on a national scale and could potentially be used to estimate the associated money turnover.

\section{Conclusion}

Because illicit drug consumption is a complex phenomenon, the indicators considered in this study can only provide a partial perspective of the phenomenon and all suffer from limitations and uncertainties. Survey data may be biased by differential responses due to stigmatisation and hidden behaviours, which are particularly pronounced for heroin and cocaine, whereas cannabis and other stimulants might be less affected. Offence data are obviously biased by law enforcement activities and strategies as well as the visibility of the drug scene and thus, may not be representative of the size of the drug using population. Munich is a clear example: offence rates related to all considered substances were amongst the highest while prevalence and wastewater data suggest low numbers of users and quantities. Moreover, this type of data does not always allow to distinguish between users and dealers (who might confess personal use to avoid charges for trafficking). Finally, wastewater analyses allow estimating the amount and type of products consumed by the community, yet they are not capable of estimating the number and type of consumers.

These limitations might explain the dissimilarities observed for cocaine-related data. As a result of its negative connotation and hidden consumption, it is likely more difficult to capture regular and marginalised users with current survey methods. Additionally, drug-related public nuisances influence the activities of law enforcement, making it difficult to draw conclusions from the number of reported offences. On the contrary, an interesting overlap could be highlighted for data related to cannabis, suggesting relatively homogeneous consumption across Germany and Switzerland. The findings support the hypothesis that cannabis consumption is less stigmatised and more widespread, and that current methods and wastewater analysis provide a realistic perspective of the situation. Similarly, a good overlap was observed for ATS-related data. A more widespread recreational use and thus, a limited number of regular/heavy users (difficult to measure) might explain the good agreement between the considered indicators. For Germany, prevalence data was not substance-specific (i.e. not possible to distinguish between amphetamine, methamphetamine and MDMA) and wastewater analysis provided a valuable tool to highlight geographical differences. Similarly, in Switzerland, where no recent survey was available, wastewater analysis allowed to identify geographical differences in amphetamine and methamphetamine use. Amphetamine was found to be more predominant in Germany and cocaine in Switzerland, confirming the northsouth gradient of stimulants use in Europe (i.e. amphetamine being the main stimulant in northern countries, while cocaine is more widespread in the south of Europe; EMCDDA, 2015d, 2014). Nonetheless, it would be necessary to include additional areas, in particular for Germany, in order to obtain a more precise image of the situation at the national level.

The findings support some of the existing hypotheses about regional features, but also provide additional evidence about geographical particularities. Understanding illicit drug consumption on a national scale remains a difficult task, however, the results of this research illustrate how the combination of different and complementary data sources allows for obtaining a more accurate picture of the situation. The retrieved information can be used to monitor changes in drug use, both at the national and international scale, identify potential dangers, promote the setup of specific interventions (e.g. targeted surveys, prevention campaigns and/or police actions), understand the structure of drug markets and guide future drug policies. Although wastewater analysis does not provide direct information about users, its ability to provide close to real-time data and its potential integration in existing 
monitoring programmes make it a valuable tool to help understanding illicit drug consumption.

\section{Role of funding source}

$$
\text { Nothing to declare. }
$$

\section{Contributors}

$\mathrm{CO}$ and $\mathrm{FB}$ planned and designed the study with contributions from $\mathrm{LBi}, \mathrm{FZ}, \mathrm{MPS}, \mathrm{AB}, \mathrm{FH}, \mathrm{OD}$ and PE. CO, FB and LBi organised the collection of the wastewater samples which were analysed by FB, LBi, LBe, JDB, AMBC and SC. FB, LK and FZ retrieved the epidemiological data used in the study. FB performed data analysis and interpreted the results with substantial contribution from all co-authors. FB, with contributions from LBi, drafted the manuscript, which was critically revised by all co-authors. All authors are aware of the content, and accept responsibility, for the manuscript.

\section{Conflict of interest}

\section{No conflict declared.}

\section{Acknowledgements}

The authors would like to thank the personnel of the wastewater treatment plants for their collaboration in providing the samples. The authors would like to thank Philippe Hayot, from the Swiss Federal Statistical Office, and Gerhard Gmel and Luca Notari, from Addiction Suisse, for providing drug-related statistics. The University Jaume I acknowledges the financial support from Generalitat Valenciana (Group of Excellence Prometeo II 2014/023); ISIC 2012/16 and from the Spanish Ministry of Economy and Competitiveness (Project Ref. CTQ2012-36189).

\section{Appendix A. Supplementary data}

Supplementary data associated with this article can be found, in the online version, at http://dx.doi.org/10.1016/j.drugalcdep.2016. 02.002 .

\section{References}

Amundsen, E.J., Reid, M.J., 2014. Self-reports of consumption of amphetamines: cocaine and heroin in a survey among marginalized drug users. Sci. Total Environ. 487, 740-745.

Banta-Green, C., Field, J., 2011. City-wide drug testing using municipal wastewater: a new tool for drug epidemiology. Significance 8, 70-74

Been, F., Benaglia, L., Lucia, S., Gervasoni, J.-P., Esseiva, P., Delémont, O., 2015. Data triangulation in the context of opioids monitoring via wastewater analyses. Drug Alcohol Depend. 151, 203-210.

Berset, J.D., Brenneisen, R., Mathieu, C., 2010. Analysis of llicit and illicit drugs in waste, surface and lake water samples using large volume direct injection high performance liquid chromatography-electrospray tandem mass spectrometry (HPLC-MS/MS). Chemosphere 81, 859-866.

Bijlsma, L., Emke, E., Hernández, F., de Voogt, P., 2012. Investigation of drugs of abuse and relevant metabolites in Dutch sewage water by liquid chromatography coupled to high resolution mass spectrometry. Chemosphere 89, 1399-1406.

Bijlsma, L., Beltrán, E., Boix, C., Sancho, J.V., Hernández, F., 2014. Improvements in analytical methodology for the determination of frequently consumed illicit drugs in urban wastewater. Anal. Bioanal. Chem. 406, 4261-4272.

Bramness, J.G., Reid, M.J., Solvik, K.F., Vindenes, V., 2014. Recent trends in the availability and use of amphetamine and methamphetamine in Norway. Forensic Sci. Int. 246, 92-97.

Castiglioni, S., Zuccato, E., Crisci, E., Chiabrando, C., Fanelli, R., Bagnati, R., 2006. Identification and measurement of illicit drugs and their metabolites in urban wastewater by liquid chromatography-tandem mass spectrometry. Anal. Chem. 78, 8421-8429.

Federal Council, 2013. Amende d'ordre pour la consommation de cannabis [Administrative fine for the consomption of cannabis] [WWW Document] https://www.news.admin.ch/message/index.html?lang=fr\&msg-id=49053 (accessed on 01.08.16).

EMCDDA, 2014. European Drug Report 2014. European Monitoring Centre for Drugs and Drug Addiction, Lisbon.

EMCDDA, 2015a. Key Indicators [WWW Document]. http://www.emcdda.europa. eu/themes/key-indicators.

EMCDDA, 2015b. Perspectives on drugs: wastewater analysis and drugs-results from a European multi-city study [WWW Document]. http://www.emcdda. europa.eu/topics/pods/waste-water-analysis (accessed on 01.08.16). EMCDDA, 2015c. European Drug Report: Trends and Developments. EMCDDA, 2015d. European Drug Report 2015.

Gmel, G., Kuendig, H., Notari, L., Gmel, C., 2014. Monitorage suisse des addictions-Consommation d'alcool, tabac et drogues illégales en Suisse en 2013 [Swiss Monitoring of Addictions-Alcohol, Tobacco and Illegal Drugs Consumption in Switzerland in 2013]. Addiction Suisse.

Jones, H.E., Hickman, M., Kasprzyk-Hordern, B., Welton, N.J., Baker, D.R., Ades, A.E., 2014. Illicit and pharmaceutical drug consumption estimated via wastewater analysis. Part B: placing back-calculations in a formal statistical framework. Sci. Total Environ. 487, 642-650.

Khan, U., Nicell, J.A., 2011. Refined sewer epidemiology mass balances and their application to heroin, cocaine and ecstasy. Environ. Int. 37, 1236-1252.

Khan, U., Nicell, J.A., 2012. Sewer epidemiology mass balances for assessing the illicit use of methamphetamine, amphetamine and tetrahydrocannabinol. Sci. Total Environ. 421-422, 144-162.

Kraus, L., Augustin, R., Tschernich, S., 2001. Repräsentativerhebung zum Gebrauch psychoaktiver Substanzen in Nordrhein-Westfalen 2000 [Population Survey of the Consumption of Psychoactive Substances in North Rhine-Westphalia 2000] (No. 120).

Kraus, L., Pabst, A., Piontek, D., 2010a. Epidemiologischer Suchtsurvey 2009: Repräsentativerhebung zum Gebrauch und Missbrauch psychoaktiver Substanzen bei Erwachsenen in Bayern [2009 Epidemiological Survey on Substance Abuse in the Adult Population of Bavaria] (No. 176).

Kraus, L., Pabst, A., Piontek, D., 2010b. Epidemiologischer Suchtsurvey 2009: Repräsentativerhebung zum Gebrauch und Missbrauch psychoaktiver Substanzen bei Erwachsenen in Sachsen. [2009 Epidemiological Survey on Substance Abuse in the Adult Population of Saxony].

Kraus, L., Rösner, S., Baumeister, S.E., et al., 2014. Epidemiologischer Suchtsurvey 2012: Repräsentativerhebung zum Gebrauch und Missbrauch psychoaktiver Substanzen bei Jugendlichen und Erwachsenen in Berlin [2012 Epidemiological Survey of Substance Abuse in the Adolescent and Adult Population of Berlin] (No. 185).

Kraus, L., Steppan, M., Piontek, D., 2015. Schätzung der Prävalenz substanzbezogener Störungen in Berlin: Opioide Kokain und Stimulanzien [Prevalence estimates of substance use disorders in Berlin: opioids, cocaine and stimulants].

Meyer, M.R., Vollerthun, T., Hasselbach, R., 2015. Prevalence and distribution patterns of amphetamine and methamphetamine consumption in a federal state in Southwestern Germany using wastewater analysis. Drug Alcohol Depend. 156, 311-314.

Ort, C., Lawrence, M.G., Reungoat, J., Mueller, J.F., 2010a. Sampling for PPCPs in wastewater systems: Comparison of different sampling modes and optimization strategies. Environ. Sci. Technol. 44, 6289-6296.

Ort, C., Lawrence, M.G., Rieckermann, J., Joss, A., 2010b. Sampling for pharmaceuticals and personal care products (PPCPs) and illicit drugs in wastewater systems: Are your conclusions valid? A critical review. Environ. Sci. Technol. 44, 6024-6035.

Ort, C., van Nuijs, A.L.N., Berset, J.-D., Bijlsma, L., Castiglioni, S., Covaci, A., de Voogt, P., Emke, E., Fatta-Kassinos, D., Griffiths, P., Hernández, F., González-Mariño, I., Grabic, R., Kasprzyk-Hordern, B., Mastroianni, N., Meierjohann, A., Nefau, T., Östman, M., Pico, Y., Racamonde, I., Reid, M., Slobodnik, J., Terzic, S., Thomaidis, N., Thomas, K.V., 2014. Spatial differences and temporal changes in illicit drug use in Europe quantified by wastewater analysis: wastewater data covering 24.74 million people. Addiction 109, 1338-1352.

Pabst, A., Kraus, L., Matos, E.G., de Piontek, D., 2013. Substanzkonsum und substanzbezogene Störungen in Deutschland im Jahr 2012 [Substance use and substance-related disorders in Germany in 2012]. SUCHT 59, 321-331.

Reid, M.J., Langford, K.H., Mørland, J., Thomas, K.V., 2011. Analysis and interpretation of specific ethanol metabolites ethyl sulfate, and ethyl glucuronide in sewage effluent for the quantitative measurement of regional alcohol consumption. Alcohol.: Clin. Exp. Res. 35, 1593-1599.

Reid, M.J., Langford, K.H., Grung, M., Gjerde, H., Amundsen, E.J., Morland, J., Thomas, K.V., 2012. Estimation of cocaine consumption in the community: a critical comparison of the results from three complimentary techniques. BMJ Open 2, e001637.

Social and Market Research Institute, Addiction Suisse, 2015. Continuous Rolling Survey of Addictive Behaviours and Related Risks.

Swiss Federal Statistical Office, 2014. Population size and population composition [WWW Document]. http://www.bfs.admin.ch/bfs/portal/en/index/themen/01/ 02/blank/key/bevoelkerungsstand/01.html (accessed on 01.08.16).

Thomas, K.V., Bijlsma, L., Castiglioni, S., Covaci, A., Emke, E., Grabic, R., Hernández, F., Karolak, S., Kasprzyk-Hordern, B., Lindberg, R.H., Lopez de Alda, M., Meierjohann, A., Ort, C., Pico, Y., Quintana, J.B., Reid, M., Rieckermann, J., Terzic, S., van Nuijs, A.L.N., de Voogt, P., 2012. Comparing illicit drug use in 19 European cities through sewage analysis. Sci. Total Environ. 432, 432-439.

Please cite this article in press as: Been, F., et al., Assessing geographical differences in illicit drug consumption-A comparison of results from epidemiological and wastewater data in Germany and Switzerland. Drug Alcohol Depend. (2016), http://dx.doi.org/10.1016/j.drugalcdep.2016.02.002 